\title{
Surfactant-mediated growth of ultrathin Ge and Si films and their interfaces: Interference- enhanced Raman study
}

\author{
S. Kanakaraju \\ Department of Instrumentation, Indian Institute of Science, Bangalore-560 012, India \\ A. K. Sood \\ Department of Physics, Indian Institute of Science, Bangalore-560 012, India \\ S. Mohan \\ Department of Instrumentation, Indian Institute of Science, Bangalore-560 012, India
}

\begin{abstract}
We report on the growth and interfaces of ultrathin polycrystalline Ge and Si films when they are grown on each other using ion beam sputter deposition with and without surfactant at different growth temperatures, studied using interference enhanced Raman spectroscopy. Ge films grown on Si without surfactant show Ge segregation at the interfaces forming an alloy of $\mathrm{Ge}_{x} \mathrm{Si}_{1-x}$ as indicated by the Ge-Si Raman mode. However, use of $\mathrm{Sb}$ as surfactant strongly suppresses the intermixing. Also Si films grown on Ge have been observed to crystallize at low-substrate temperatures in the presence of the surfactant. In contrast to the growth of $\mathrm{Ge}$ on $\mathrm{Si}$, the intermixing in the growth of $\mathrm{Si}$ on Ge is observed to be negligibly small even without the surfactant layer.
\end{abstract}

\section{INTRODUCTION}

Ultrathin semiconductor film structures are attracting a lot of interest due to their novel properties and potential applications arising from band-gap engineering. ${ }^{1-6}$ Guntzmann and Clauseker, ${ }^{7}$ in their calculation based on the quantum confinement, speculated the possibility of realizing the direct band gap from indirect band gap materials, which have been achieved in superlattices ${ }^{1-6}$ and nanocrystals. ${ }^{8,9} \mathrm{Si}$ - and Ge-based superlattices are being extensively investigated, as their optoelectronic devices can be easily integrated with the well established Si-based IC technologies. Despite the fact that a number of methods have been employed to grow these structures, their applications are slow to follow due to the problem of segregation of $\mathrm{Ge}$ into the underlying $\mathrm{Si}$, which smears the sharp interfaces. Among the efforts to overcome this problem, surfactant mediated growth ${ }^{10}$ (SMG) is proving to be very useful.

In this process of SMG, a third element is introduced over the substrate surface before the film growth, which modifies the surface free energy. Further, during the film growth, the surfactants are observed to segregate and come up to the surface of the growing film and continue to modify the surface. Although there are numerous reports ${ }^{11-22}$ on SMG, the exact microscopic phenomena involved in its action is as yet unresolved. Various in situ and ex situ studies such as medium energy ion scattering, ${ }^{10,17,21}$ reflection high-energy electron diffraction ${ }^{16}$ transmission electron microscopy (TEM) ${ }^{18}$ x-ray reflectivity, ${ }^{15}$ and Raman ${ }^{14}$ etc. have been used to understand this. The investigations evidenced a change in surface diffusion lengths of the depositing species, which hinder the island formation as well as crossover from two-dimensional (2D) to 3D islands. Our interest is to investigate the influence of $\mathrm{Sb}$ as a surfactant on the growth and interfaces of Si and Ge using Raman spectroscopy. In the study of Ge segregation into $\mathrm{Si}$, Raman spectroscopy is a very useful method as it directly identifies the $\mathrm{Si}-\mathrm{Ge}$ vibrational mode ${ }^{4}$ at $\sim 400 \mathrm{~cm}^{-1}$. Apart from this, Raman spectroscopy can be used to qualitatively understand the degree of crystallinity and the nature of interfaces. Raman investigations on surfactant mediated growth of Ge and Si are very limited which may be due to the limitations of poor signal to noise ratio in the nonresonant conventional backscattering geometry. A lower penetration depth of the exciting visible light can also prevent the investigation of deep buried layer interfaces. Interference enhanced Raman spectroscopy ${ }^{23,24}$ (IERS) overcomes these limitations to a great extent by trapping a larger amount of light in ultra thin layer(s) (as well as in their interfaces) using a multilayer structure in which the semiconductor film(s) (and their interface) to be studied are well within the penetration depth of the exciting light. In this multilayer structure three different optical functions are present: (i) The bottom layer is a reflector (normally $\mathrm{Al}$ ) for the exciting laser frequency $(\lambda)$, (ii) the layer above that is a transparent dielectric film (normally $\mathrm{SiO}_{2}$ ) which introduces the required phase shift. (hence, also called as phase layer) and (iii) The ultrathin absorbing (for $\lambda$ ) layer(s) to be investigated is(are) grown over the dielectric film. In this structure, if the total optical thickness of the dielectric layer plus the absorbing layer(s) is equal to $\lambda / 4$, then an effective antireflection condition is achieved. Since the base layer is a good reflector and the absorption of the dielectric layer is negligible, most of the incident light is absorbed in the ultra thin layer(s) (as well as in their interfaces).

In this paper, we report on Raman investigations of ultra thin polycrystalline $\mathrm{Si}$ and $\mathrm{Ge}$ films growth and their interface, when they are grown on each other at different temperatures, with and without the surfactant Sb using IERS. In our experiments we have used $\mathrm{CeO}_{2}$ as phase layer instead of conventionally used $\mathrm{SiO}_{2}$ and the reasons have been dis- 
cussed in an earlier report. ${ }^{25}$ Since the aim of our investigation is to study the $\mathrm{Si}$ and $\mathrm{Ge}$ interfaces grown up to $600^{\circ} \mathrm{C}$ $\mathrm{Al}$ cannot be used as a reflector, as it is not stable at high temperatures and, therefore, it has been replaced by Pt. Based on this idea, after a detailed calculation of reflectivity of various thickness combinations using the transfer matrix method for multilayer thin films, we have selected the structures of $35 \AA \mathrm{Ge} / 35 \AA \mathrm{Si} / 160 \AA \mathrm{CeO}_{2} / 1500 \AA \mathrm{Pt} / \mathrm{substrate}$ and $35 \AA \mathrm{Si} / 35 \AA \mathrm{Ge} / 160 \AA \mathrm{CeO}_{2} / 1500 \AA \mathrm{Pt} /$ substrate. For surfactant mediated growth, a thin layer of $\mathrm{Sb}(5 \AA)$ was grown in between $\mathrm{Si}$ and Ge layers.

\section{EXPERIMENTAL DETAILS}

Films have been prepared by ion beam sputter deposition process whose details have been reported elsewhere. ${ }^{26}$ In brief, a Pt foil of 2 in diameter and $0.5 \mathrm{~mm}$ thickness was bonded to a copper plate and used as a target. The target has been sputtered with ion energy of $1 \mathrm{KeV}$ and current of 25 $\mathrm{mA}$ and the Pt films were deposited on an optically polished quartz substrate. $\mathrm{CeO}_{2}$ films have been deposited from a stoichiometric $\mathrm{CeO}_{2}$ target of $40 \mathrm{~mm}$ diameter. Ion energy of 1 $\mathrm{KeV}$ and current of $20 \mathrm{~mA}$ were used to sputter the target and the estimated rate of deposition was $0.5 \AA / s{ }^{26}$ The partial pressure of oxygen was maintained at $1 \times 10^{-4}$ mbar for obtaining absorption free $\mathrm{CeO}_{2}$ films. ${ }^{26}$ For SMG, antimony $(\mathrm{Sb})$ of nominal layer thickness of $5 \AA$ has been deposited at a rate of $\sim 0.1 \AA / \mathrm{s}$ using Ar ion beam with an energy of 0.5 $\mathrm{KeV}$ and current of $5 \mathrm{~mA}$. Si and Ge films were deposited at a rate of $0.3 \AA / s$ and $0.26 \AA / s$, respectively. ${ }^{27}$ The rate of depositions were estimated from the growth calibration curves obtained using talysurf and $\mathrm{x}$-ray reflectivity measurements. ${ }^{27}$ The nominal thickness of the Si layer was estimated to be $35 \pm 3 \AA$ and $35 \pm 4 \AA$ for $\mathrm{Ge}^{27}$ For the $\mathrm{Si} / \mathrm{Ge} / \mathrm{CeO}_{2} / \mathrm{Pt} / \mathrm{Subst}$. samples the top $\mathrm{Si}$ layer has been protected from oxidation with a 50- $\AA$ cap layer of $\mathrm{CeO}_{2}$.

For Raman investigations, the samples were excited at room temperature using the $5145 \AA$ line of an $\mathrm{Ar}^{+}$ion laser with low power of $\sim 2 \mathrm{~mW}$ in order to avoid any sample heating. A Dilor XY Raman spectrometer equipped with a triple monochromator and liquid nitrogen cooled charge coupled device (CCD) detector has been used to record Raman spectra in near backscattering geometry.

\section{RESULTS AND DISCUSSION}

\section{A. Growth of Ge on Si without surfactant}

Figure 1(a) shows the Raman spectra of $35 \AA$ Ge/35 $\AA$ $\mathrm{Si} / \mathrm{CeO}_{2} / \mathrm{Pt} / \mathrm{Substrate}$ structures in which crystalline $\mathrm{Si}$ films have been grown at $550^{\circ} \mathrm{C}$ over the $\mathrm{CeO}_{2}$ films. Following this the Ge films have been deposited at different substrate temperatures $\left(T_{s}\right)$ as indicated in Fig. 1(a). The Ge films grown at a substrate temperature of $300{ }^{\circ} \mathrm{C}$ show a sharp optical phonon line at $298 \mathrm{~cm}^{-1}$, the broad shoulder over the low frequency side indicates that the amorphous Ge coexists with crystalline Ge. A weak peak seen at $\sim 464 \mathrm{~cm}^{-1}$ in some of the spectra are due to the triply degenerate Raman active $F_{2 g}$ mode of ceria. ${ }^{28}$ The Ge films grown at higher substrate temperatures $\left(>300^{\circ} \mathrm{C}\right)$ did not show the amorphous Ge band $\left(\sim 277 \mathrm{~cm}^{-1}\right)$, implying that the films are completely crystalline. The Raman lines of the Ge films were
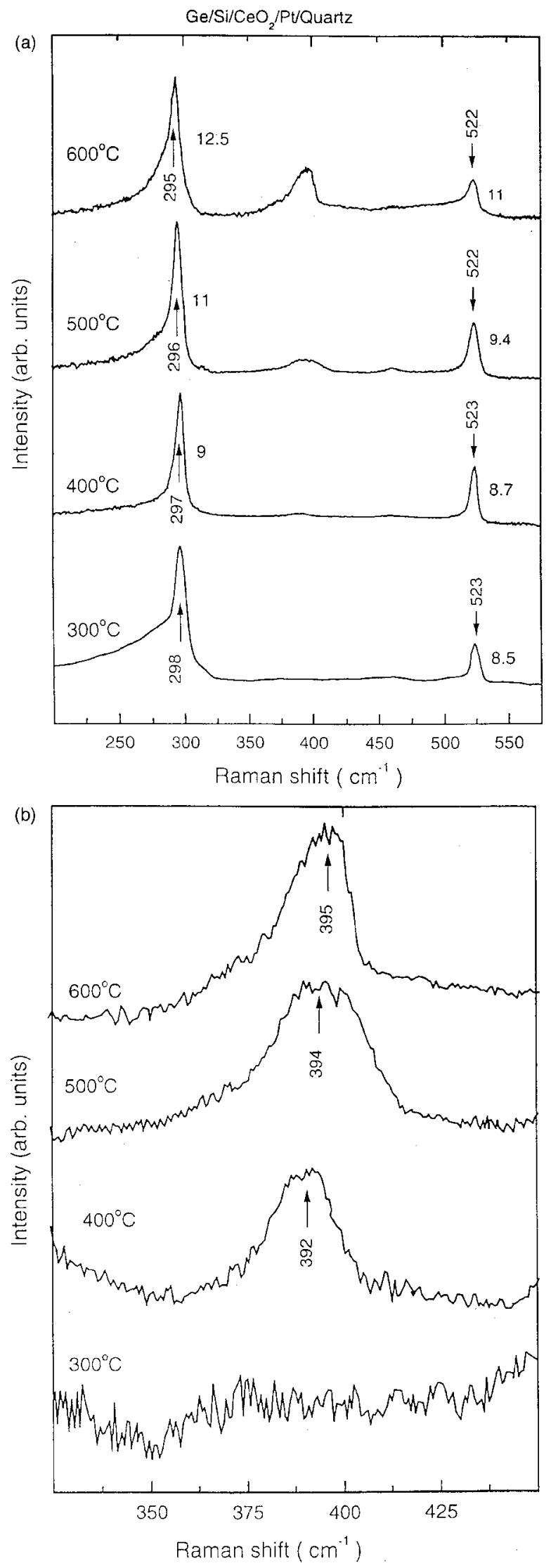

FIG. 1. (a) IERS spectra of Ge grown on bare Si. The numbers near the peaks state their FWHM. (b) IERS spectra of Ge grown on bare Si [Fig. 1(a) expanded in $X$ and $Y$ scales]. 
redshifted compared to that of bulk Ge at $299 \mathrm{~cm}^{-1}$ as well as asymmetrically broadened. With increasing growth temperature, the full width of half maximum (FWHM) $(\Gamma)$ of the Ge-Ge peak as marked in Fig. 1(a), as well as its asymmetry and redshift increased. The reason for the asymmetrical broadening and redshift can be due to the phonon confinement effect. ${ }^{29}$ Further, growth of $\mathrm{Ge}$ on $\mathrm{Si}$ can lead to the formation of $\mathrm{Ge}_{x} \mathrm{Si}_{1-x}$ alloy at the interface. ${ }^{30}$ The intermixing can be more clearly inferred from the Ge-Si vibrational mode that appears at $\sim 400 \mathrm{~cm}^{-1}$. [Figure 1(b) was obtained from Fig. 1(c) by expanding both the abscissa and ordinates scales.] The films deposited at $300^{\circ} \mathrm{C}$ did not show any peak corresponding to $\mathrm{Ge}-\mathrm{Si}$ mode, whereas, the films deposited at higher temperatures show them. With the increase in growth temperature, the intensity of the Ge-Si peak increases confirming the enhanced Ge segregation at the interfaces. The phonon frequencies and their intensity ratios can be used to estimate the alloy composition, strain and thickness of each layer. Pearson et al. ${ }^{31}$ have estimated the effective thicknesses of the interface alloy, $\mathrm{Si}$ and Ge layers in amorphous $(a-) \mathrm{Si} / a-\mathrm{Ge}$ superlattices from the relative Raman intensities. Applying Pearson's model to our case may not be correct, because of the IERS structure used in which, the increased absorption in each layer may not be in same proportion as in conventional superlattices. Groenen et al. ${ }^{32}$ have reported a linear dependence of $x$ with the intensity ratio of $\mathrm{GeGe} / \mathrm{SiGe}$ and $\mathrm{SiGe} / \mathrm{SiSi}$ modes. Renucci, Renucci, and Cardona ${ }^{33}$ have studied these Raman frequencies as a function of composition $x$ for bulk alloy. Both the Ge-Ge and $\mathrm{Si}$-Si modes lower in frequency with increase of $x$. However, the Ge-Si mode shows an increase in blueshift up to $x$ $\sim 0.5$, which decreases with further increase of $x$. Once again, these methods cannot be applied to the present case due to the IERS structure. We note that though the intensity of the $\mathrm{SiGe}$ mode is significant for the samples grown at 500 and $600{ }^{\circ} \mathrm{C}$, the alloy line due to $\mathrm{Si}-\mathrm{Si}$ at $\sim 470 \mathrm{~cm}^{-1}$, as reported by Schorer et al. ${ }^{34}$ was not observed. It may have merged with the Raman line of $\mathrm{CeO}_{2}$ at $\sim 467 \mathrm{~cm}^{-1}$. The Raman line associated with $\mathrm{Si}$ optical phonons was blueshifted $\left(+1 \mathrm{~cm}^{-1}\right)$ with respect to the bulk $\left(522 \mathrm{~cm}^{-1}\right)$ which can be due to the residual compressive strain developed in $\mathrm{Si}$ films when grown on $\mathrm{CeO}_{2}$, due to the lattice mismatch of $\sim-0.4 \%$ between $\mathrm{Si}$ and $\mathrm{CeO}_{2}$.

\section{B. Growth of Ge on Si with $\mathrm{Sb}$ as surfactant}

Figure 2(a) shows IERS spectra of Ge films grown at different substrate temperatures $\left(T_{s}\right)$ on $\mathrm{Si}$ with $\mathrm{Sb}$ as surfactant. Unlike in the previous case, the presence of surfactant enabled the growth of pure crystalline $\mathrm{Ge}$ film on $\mathrm{Si}$ at the substrate temperature of $300^{\circ} \mathrm{C}$. In general, SMG resulted in better crystalline Ge film growth as inferred from the relative lower linewidth of the $300 \mathrm{~cm}^{-1}$ Raman line, mentioned in the figure [compare Figs. 2(a) and 1(a)]. Table I compares the $\Gamma$ and $\delta \omega$ values of the films deposited with and without surfactant as a function of substrate temperature. Surfactant induced modification in growth can also be seen from the Raman peak positions. The films grown without surfactant display redshifted Ge line whereas it is blueshifted while grown with surfactant. This can be understood qualitatively in terms of strained layer growth. For example,
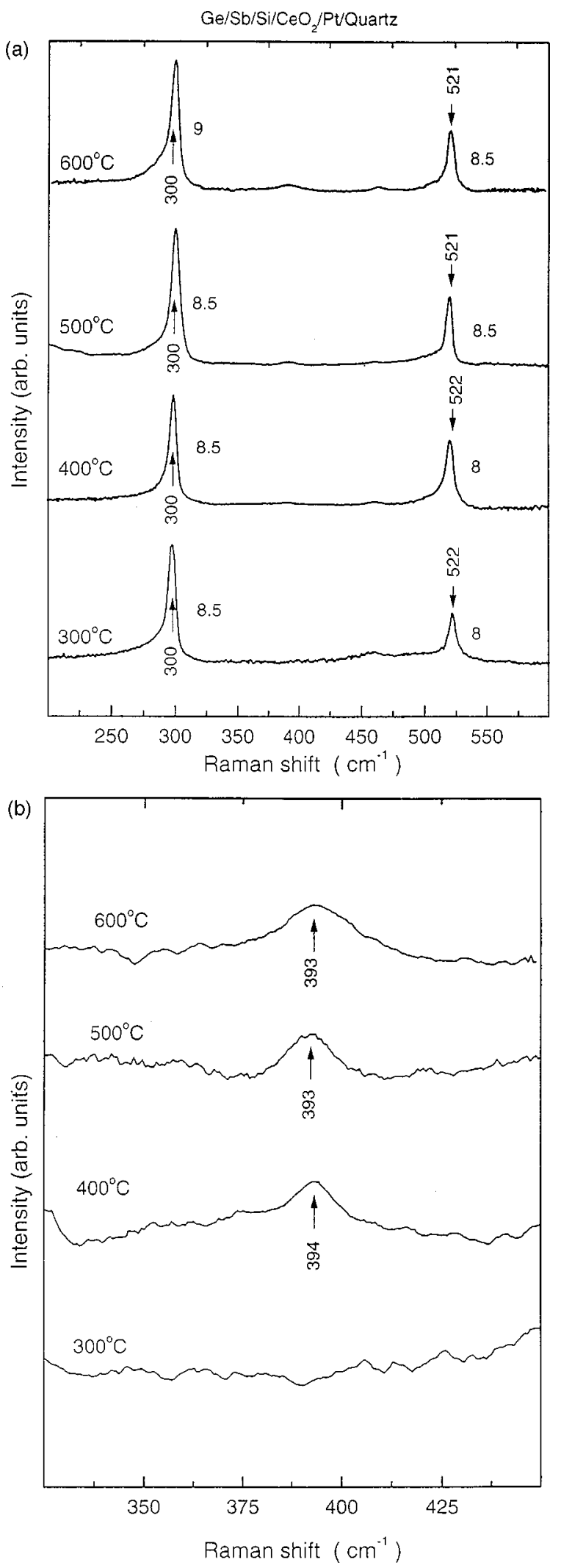

FIG. 2. (a) IERS spectra of Ge grown on $\mathrm{Si}$ with $\mathrm{Sb}$ as surfactant. The numbers near the peaks state their FWHM. (b) Figure 2(a) expanded in $X$ and $Y$ scales.

in a lattice mismatched heteroepitaxial system, the use of surfactant was found to increase critical thickness even at lower substrate temperatures. In general, lattice mismatch favors strain relaxation through island formation. The surfac- 
TABLE I. $\delta \omega$ and $\Gamma$ of Ge films grown at different substrate temperatures on $\mathrm{Si}$ with and without surfactant.

\begin{tabular}{cccccc}
\hline \hline \multirow{2}{*}{$\begin{array}{c}\text { Growth } \\
\text { Temperature }\left({ }^{\circ} \mathrm{C}\right)\end{array}$} & \multicolumn{2}{c}{ Without surfactant } & & \multicolumn{2}{c}{ With surfactant } \\
\cline { 2 - 3 } \cline { 5 - 6 } & $\delta \omega\left(\mathrm{cm}^{-1}\right)$ & $\Gamma\left(\mathrm{cm}^{-1}\right)$ & & $\delta \omega\left(\mathrm{cm}^{-1}\right)$ & $\Gamma\left(\mathrm{cm}^{-1}\right)$ \\
\hline 300 & -1.5 & - & & +1.5 & 8.0 \\
400 & -2.5 & 11 & & +1.5 & 7.5 \\
500 & -4.0 & 12.5 & & +1.3 & 7.7 \\
600 & -5 & & +1.3 & 8.2 \\
\hline \hline
\end{tabular}

tant layer hinders this islanding process and permits layer by layer growth, in which the films are coherently strained. For a lattice mismatch of $\sim-4.2 \%$ between $\mathrm{Ge}$ and $\mathrm{Si}$ coherently strained Ge layer growth should blueshift the phonon line by $\sim+17 \mathrm{~cm}^{-1}$. Sutter et al. ${ }^{30}$ reported that in strained layer superlattices of $\mathrm{Si}$ and $\mathrm{Ge}$, the phonon line of $\mathrm{Ge}$ was shifted by $13 \mathrm{~cm}^{-1}$, which was interpreted as due to the resultant shift of compressive strain and the phononconfinement effect. In our investigations, the magnitude of the observed blueshift is much less than $17 \mathrm{~cm}^{-1}$. This relatively small blueshift is because the grown layers are polycrystalline and which does not allow the growth of coherently strained films. Further, the redshift due to phonon confinement will also compensate to some extent the blueshift due to compressive strain.

The phonon line broadening is very sensitive to the crystallite size or island size and is a measure of the film quality. In contrast to the films grown without surfactant ( $\Gamma$ from 9 to $13 \mathrm{~cm}^{-1}$ ) the Raman linewidth for SMG samples are in the range of 7.5 to $8.4 \mathrm{~cm}^{-1}$ (see Table I). This implies that the grains are larger compared to that of films deposited without surfactant. Such surfactant induced large grain growth has been reported by Eaglesham, Unterwald, and Jacobson ${ }^{35}$ in their XTEM investigations covering the annealing effects on $\mathrm{Ge} / \mathrm{Si}$ in the presence of various impurities ( $\mathrm{H}, \mathrm{In}$, and $\mathrm{Sb}$ ). Among the impurities, $\mathrm{Sb}$ was reported to be most effective in slowing down the process of islanding in post growth annealing. It was reported to favor large flat islands as well as to reduce the island spacing by hundred fold, compared to the Ge films grown on bare Si surface. The mechanism by which the prohibition of islanding occurs is still controversial. Copel et al. ${ }^{10,17}$ proposed that the adherence of growing species on surfactant passivated surface results in a large decrease of their surface mobility which in turn hinders the formation of islands as well as reduces the interdiffusion of Ge into Si. In other reports, ${ }^{22,36,37} \mathrm{SMG}$ has been explained based on a new proposal of the two-dimer correlated exchange mechanism. On the other hand, (ab initio) molecular dynamics $^{38}$ reveals that the surfactant significantly reduces the diffusion barrier near the step edge and hence the island formation is suppressed. We also note that the observed $\Gamma$ in Fig. 2(a) is slightly greater than that of bulk Ge $\left(5.5 \mathrm{~cm}^{-1}\right)$ which can be due to the phonon confinement effect. ${ }^{29}$

In order to see the Si-Ge mode for the case of SMG, Fig. 2(a) has been expanded in $X$ and $Y$ scales as shown in Fig. 2(b). The films deposited above $300^{\circ} \mathrm{C}$ show relatively week peaks at $\sim 400 \mathrm{~cm}^{-1}$ in comparison with Fig. 1(b), which indicates the use of $\mathrm{Sb}$ as surfactant has reduced or suppressed the Ge segregation into Si. Also the peaks in Fig. 2(b) are narrower than in Fig. 1(b), implying smoother interface in SMG films. This inference is similar to the earlier report. ${ }^{39}$ Katayama et $a l .{ }^{40}$ studied the influence of surfactant coverage on the film quality and interfaces of Ge/Si. An increase of surfactant coverage was reported to be better in suppressing the intermixing of $\mathrm{Ge}$ and $\mathrm{Si}$, Horn-von Hoegen et $a l .{ }^{41}$ did not observe the interface vibrational mode for the surfactant mediated molecular-beam epitaxy (MBE) grown $\mathrm{Ge}$ on $\mathrm{Si}$ at $600{ }^{\circ} \mathrm{C}$, again implying smooth interfaces. This is because the observation of interface mode in Raman spectra recorded in backscattering geometry requires the breakdown of wave vector selection rule arising from interface roughness. Dondl et al. ${ }^{14}$ investigated the Ge/Si interface with $\mathrm{Sb}$ and Sn as surfactant using Auger and Raman. According to them, use of $\mathrm{Sb}$ as surfactant had retained the superlattice structure as confirmed from acoustic phonons.

\section{Growth of Si on Ge without surfactant}

Figure 3(a) shows the Raman spectra of $\mathrm{Si}$ grown on $\mathrm{Ge} / \mathrm{CeO}_{2} / \mathrm{Pt} /$ subst. at different substrate temperatures. In this part of the investigation, all the crystalline $\mathrm{Ge}$ films were deposited at $\sim 400{ }^{\circ} \mathrm{C}$. Si films deposited at $400{ }^{\circ} \mathrm{C}$ on $\mathrm{Ge}$ show only the optical phonon line at $488 \mathrm{~cm}^{-1}$ due to the amorphous nature of $\mathrm{Si}$. For the films deposited at $450{ }^{\circ} \mathrm{C}$, the phonon line due to both amorphous and crystalline $\mathrm{Si}$ are seen which, indicates the coexistence of amorphous and crystalline Si. With increase of the substrate temperature to $500{ }^{\circ} \mathrm{C}$, the peak intensity of crystalline $\mathrm{Si}$ at $523 \mathrm{~cm}^{-1}$ increased however, the presence of amorphous $\mathrm{Si}$ can still be seen from the broad shoulder occurring at $\sim 490 \mathrm{~cm}^{-1}$ even at growth temperature of $500{ }^{\circ} \mathrm{C}$.

Considering the Ge optic phonon lines shown in Fig. 3(a), they are all blueshifted compared to that of bulk Ge at 299 $\mathrm{cm}^{-1}$. In these samples, the Ge layer is sandwiched between $\mathrm{Si}$ and the middle $\mathrm{CeO}_{2}$ layer. With respect to both $\mathrm{Si}$ and $\mathrm{CeO}_{2}$, Ge has a lattice mismatch of $\sim 4.2 \%$ and hence the films are compressively strained. As mentioned earlier, the deposited films are only partially strained due to the polycrystalline nature of the films. Also the effect of phonon confinement cannot be ignored and the observed shift should be attributed to the combined effect of both phonon confinement and strain. As far as the interface of $\mathrm{Si} / \mathrm{Ge}$ is concerned, in general, the Ge-Si phonon line occurring at $\sim 400 \mathrm{~cm}^{-1}$ is very weak as seen in Fig. 3(b) an expanded spectra of Fig. 3(a) in $X$ and $Y$ scales. More details are to be discussed later while comparing with the films grown using surfactant $\mathrm{Sb}$. 

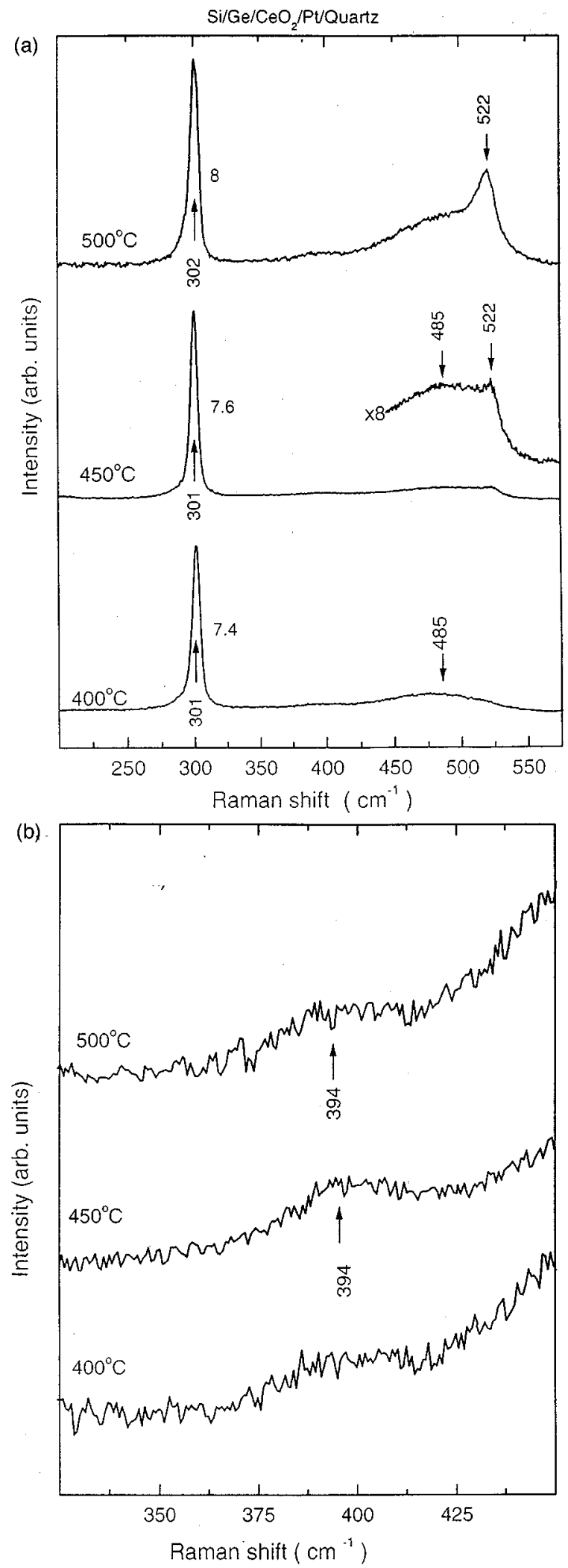

FIG. 3. (a) IERS spectra of Si grown on bare Ge. The numbers near the peaks state their FWHM. (b) Figure 3(a) expanded in $X$ and $Y$ scales.

\section{Growth of Si on Ge with Sb as surfactant}

Figure 4(a) show the Raman spectra of samples where, $\mathrm{Si}$ films have been grown at 300,400 , and $500{ }^{\circ} \mathrm{C}$ on $\mathrm{Ge} / \mathrm{CeO}_{2} / \mathrm{Pt} / \mathrm{Substrate}$ with predeposited $\mathrm{Sb}$ layer on $\mathrm{Ge}$. The
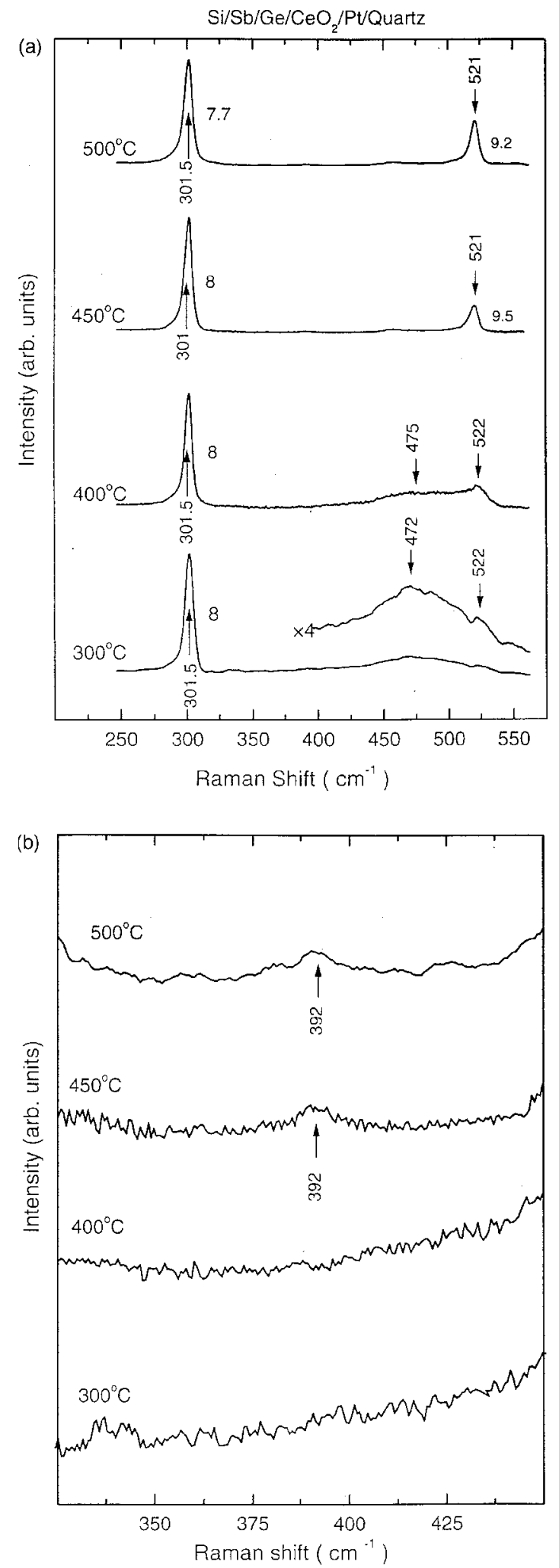

FIG. 4. (a) IERS spectra of Si on Ge grown with Sb as surfactant. The numbers near the peaks state their FWHM. (b) Figure 4(a) expanded in $X$ and $Y$ scale.

crystallization of $\mathrm{Si}$ starts even at the substrate temperature of $\sim 300^{\circ} \mathrm{C}$ as indicated from the shoulder at $522 \mathrm{~cm}^{-1}$ over the amorphous Si broad peak at $475 \mathrm{~cm}^{-1}$. Films deposited above $400{ }^{\circ} \mathrm{C}$ show only crystalline feature at $523 \mathrm{~cm}^{-1}$. While the films grown without surfactant up to $500{ }^{\circ} \mathrm{C}$ are 
not purely crystalline, the predeposited $\mathrm{Sb}$ has promoted the crystalline growth at lower substrate temperatures. The measured Raman line broadening of Si films deposited at 450 and $500{ }^{\circ} \mathrm{C}$ are $\sim 9.0 \mathrm{~cm}^{-1}$. This can be attributed to good crystalline quality or to large islands. Compared to the bulk Si Raman width $\left(4.5 \mathrm{~cm}^{-1}\right)$, the additional broadening seen in these films can be due to the phonon confinement effect. With the increase of substrate temperature there is an increase of redshift in the Si Raman line, with respect to that of bulk $\mathrm{Si}$ at $522 \mathrm{~cm}^{-1}$. This can be attributed to combined effect of: (a) The one dimensional phonon confinement along the direction of the film growth as suggested by the low frequency asymmetrical broadening of the Si Raman line. ${ }^{29}$ (b) The shift induced due to the strain. The lattice mismatch of $\sim 4.2 \%$ between $\mathrm{Si}$ and $\mathrm{Ge}$ results in tensile strain in the $\mathrm{Si}$ films, which redshift the phonon line. Due to the polycrystalline nature of the growth, the films are expected to be only partially strained and hence show a smaller redshift than expected. Now considering the $\mathrm{Si} / \mathrm{Ge}$ interfaces with surfactant, [see Fig. 4(b)] films deposited up to $400{ }^{\circ} \mathrm{C}$ did not show any Raman line at $400 \mathrm{~cm}^{-1}$. However, a weak humps $\sim 392$ $\mathrm{cm}^{-1}$ can be seen for films deposited at $450{ }^{\circ} \mathrm{C}$ and $500^{\circ} \mathrm{C}$. $\mathrm{Si}$ films grown on Ge with and without surfactant did not show a significant $\mathrm{Si}-\mathrm{Ge}$ Raman mode at $\sim 400 \mathrm{~cm}^{-1}$. In general, the Raman spectra of the interfaces deposited with and without surfactant are more or less similar and the influence of $\mathrm{Sb}$ as surfactant on the $\mathrm{Si} / \mathrm{Ge}$ interface is not significant. However, it is to be recalled that surfactant does induce the crystallization of $\mathrm{Si}$ on $\mathrm{Ge}$ at lower substrate temperatures than that on the bare Ge surface.

\section{E. Comparison of $\mathrm{Ge} / \mathrm{Si}$ and $\mathrm{Si} / \mathrm{Ge}$ growth}

The present study clearly indicates that the interface smearing occurs during the growth of $\mathrm{Ge}$ on $\mathrm{Si}$ due to the strong tendency of Ge segregation into $\mathrm{Si}$. On the other hand, for $\mathrm{Si}$ on $\mathrm{Ge}$, the phonon line of Si-Ge is very weak and indicates that the intermixing is not significant compared to $\mathrm{Ge} / \mathrm{Si}$ [see Figs. 1(b) and 3(b)]. This is similar to an earlier report $^{39}$ on the MBE growth of Si and Ge structures wherein the intermixing was seen only for $\mathrm{Ge} / \mathrm{Si}$ and the rms roughness was observed to be more for $\mathrm{Ge} / \mathrm{Si}$ than $\mathrm{Si} / \mathrm{Ge}$ growth. Similar results have been reported ${ }^{27}$ for the $\mathrm{x}$-ray reflectivity measurements of $\mathrm{Ge} / \mathrm{Si} / \mathrm{Ge}$ trilayer. The analysis of average electron density ${ }^{27}$ along the film thickness indicated an intermixing only at $\mathrm{Ge} / \mathrm{Si}$ interface, whereas, the $\mathrm{Si} / \mathrm{Ge}$ interface was sharp.

Raman lines for the Ge films seen in Figs. 1(a) and 3(a) show a distinct difference in their line shape particularly on the low-frequency side. The confinement effect on Ge phonons is the same for $\mathrm{Ge}$ on $\mathrm{Si}$ and $\mathrm{Si}$ on Ge films as their thickness are the same, but the asymmetrical broadening is more for the former [Fig. 1(a)] than the latter [Fig. 3(a)]. This is because of the free surface boundary of the Ge films grown on $\mathrm{Si}$, which show a significant contribution from the surface phonons as seen in earlier studies of bulk Ge (Ref. 42) and gas evaporated Ge microcrystals. ${ }^{43}$ Interestingly, for a microcrystallite size of $8 \mathrm{~nm}$ the Raman spectra resembled that of amorphous Ge and was attributed to the surface phonons from loosely packed microcrystals with large free surface boundary. ${ }^{43}$ In the case of $\mathrm{Si}$ on Ge [Fig. 3(a)] the free boundary condition is not satisfied and hence, the observed asymmetrical broadening in Ge phonons is purely due to the phonon confinement effect. It is, therefore, clear that surface phonon states in low dimensional systems can significantly affect the Raman line shape.

\section{CONCLUSIONS}

Interference enhanced Raman spectroscopy has been successfully used to investigate the interfaces and growth of ultra thin polycrystalline $\mathrm{Ge} / \mathrm{Si}$ and $\mathrm{Si} / \mathrm{Ge}$, with and without the surfactant $\mathrm{Sb} . \mathrm{CeO}_{2}$ has been used as a phase layer which allowed the growth of crystalline $\mathrm{Si}$ and $\mathrm{Ge}$. $\mathrm{Al}$ reflector has been replaced with $\mathrm{Pt}$, which is stable at higher substrate temperatures and in oxygen atmosphere. Ge films grown on Si without surfactant show a tendency of intermixing as confirmed by the Si-Ge Raman line. In contrast, Si grown on Ge did not show any intermixing. The use of $\mathrm{Sb}$ as surfactant for the case of Ge on Si strongly suppresses the Ge segregation, whereas, the nature of the interface for $\mathrm{Si}$ on $\mathrm{Ge}$ is not much influenced by the surfactant. The SMG of Ge films on $\mathrm{Si}$ and $\mathrm{Si}$ films on Ge induce crystallization at low substrate temperatures. A better crystalline quality of $\mathrm{Si}$ and Ge films grown with surfactant has been indicated from their sharp Raman lines. The observed Raman line shifts for both the $\mathrm{Si}$ and Ge have been attributed to the combined effect of the phonon confinement and residual strain. An additional broadening exhibited in the Ge Raman line for the case of Ge on $\mathrm{Si}$ and not in $\mathrm{Si}$ on $\mathrm{Ge}$ has been attributed to the presence of surface phonons arising under the free surface boundary conditions.

\section{ACKNOWLEDGMENTS}

We thank D.V.S. Muthu for his help in recording the Raman spectra and the Department of Science \& Technology for financial assistance.
*Present address: Dept. of Electrical Engineering, Thornton Hall, University of Virginia, Charlottesville, VA 22903.

${ }^{1}$ T. P. Pearsall, J. Bevk, L. C. Feldman, J. M. Bonar, and J. P. Mannearts, Phys. Rev. Lett. 58, 729 (1987); T. P. Pearsall, J. M. Vandenberg, E. Kasper, and H. Kibbel, ibid. 63, 2104 (1990); R. Zachai, K. Eberl, G. Abstreiter, E. Kasper, and H. Kibbel, ibid. 64, 1055 (1990); 65, 2611 (1990); U. Schid, N. E. Christensen, and M. Cardona, ibid. 65, 2610 (1990).

${ }^{2}$ Z. H. Lu, D. J. Lockwood, and J. M. Baribeau, Nature (London)
376, 258 (1995); Brian T. Sullivan, D. J. Lockwood, Henri J. Labbeand, and Z. H. Lu, Appl. Phys. Lett. 69, 3149 (1996).

${ }^{3}$ R. Manor, O. Brafman, and J. C. Bean, Appl. Surf. Sci. 102, 217 (1996); Yichan Yin, D. Yan, Fred H. Pollak, Mark S. Hybertsen, J. M. Vandenberg, and J. C. Bean, Phys. Rev. B 52, 8951 (1995); T. P. Pearsall, J. Berk, J. C. Bean, J. Bonan, and J. P. Mamaerts, and A. Ourmazd, ibid. 39, 3741 (1989).

${ }^{4}$ O. Brafman, M. A. Araujo Silva, F. Cerdeira, R. Manor, and J. C. Bean, Phys. Rev. B 51, 17800 (1995); T. P. Pearsall, Crit. Rev. 
Solid State Mater. Sci. 15, 551 (1989).

${ }^{5}$ B. Jusserand and M. Cardona, in Light Scattering in Solids, edited by M. Cardona and G. Güntherodt (Springer-Verlag, Berlin, 1989), Vol. 5.

${ }^{6}$ A. K. Sood, J. Menedez, M. Cardona, and K. Ploog, Phys. Rev. Lett. 54, 2111 (1985); 54, 2115 (1985).

${ }^{7}$ V. Guntzman and K. Clausecker, Appl. Phys. A: Solids Surf. 3, 9 (1974).

${ }^{8}$ L. T. Canham, Appl. Phys. Lett. 57, 1046 (1990).

${ }^{9}$ Y. Maeda, Phys. Rev. B 51, 1658 (1995).

${ }^{10}$ M. Copel, M. C. Reuter, Efthimius Kaxiras, and R. M. Tromp, Phys. Rev. Lett. 63, 632 (1989).

${ }^{11}$ K. Sakamoto, K. Miki, T. Sakamoto, H. Matsuhata, and K. Kyoya, J. Cryst. Growth 127, 392 (1993).

${ }^{12}$ H. J. Osten, J. Klah, G. Lippert, and E. Bugiel, J. Cryst. Growth 127, 396 (1993).

${ }^{13}$ H. J. Osten, J. Klah, G. Lippert, B. Dietrih, and E. Bugiel, Phys. Rev. Lett. 69, 450 (1992).

${ }^{14}$ W. Donl, G. Lutjening, W. Wegscheider, J. Wilhelm, R. Schorer, and G. Abstreiter, J. Cryst. Growth 127, 440 (1993).

${ }^{15}$ M. Li, Q. Curi, L. Zhang, J. M. Zhou, Z. H. Mai, C. Dong, H. Chen, and F. Wu, J. Appl. Phys. 78, 1681 (1995).

${ }^{16}$ B. Gallas, I. Berbezier, J. Cheirier, and S. Derrien, Phys. Rev. B 54, 4919 (1996).

${ }^{17}$ M. Copel, M. C. Reuter, H. Hornvon Hoegen, and R. M. Tromp, Phys. Rev. B 42, 11682 (1990).

${ }^{18}$ H. Minoda, Y. Tanishiro, N. Yamamoto, and K. Yagi, Surf. Sci. 357-358, 418 (1996).

${ }^{19}$ J. Falta, M. Copel, F. K. Legouess, and R. M. Tromp, Appl. Phys. Lett. 62, 2962 (1993).

${ }^{20}$ B. Voigtlander, A. Zinner, T. Weber, and H. P. Bonzel, Phys. Rev. B 51, 7583 (1995).

${ }^{21}$ J. Marsies and N. Grandjean, Phys. Rev. B 48, 8502 (1993).

${ }^{22}$ R. M. Tromp and M. C. Ruter, Phys. Rev. Lett. 68, 954 (1992).

${ }^{23}$ R. J. Nemanich, C. C. Tsai, and G. A. N. Connel, Phys. Rev. Lett. 44, 273 (1980).

${ }^{24}$ J. Fortner, R. Q. Yu, and J. S. Lannin, Phys. Rev. B 42, 7610 (1990).
${ }^{25}$ S. Kanakaraju, A. K. Sood, and S. Mohan, Curr. Sci. 74, 322 (1998); J. Appl. Phys. 84, 5756 (1998).

${ }^{26}$ S. Kanakaraju, S. Mohan, and A. K. Sood, Thin Solid Films 305, 191 (1997)

${ }^{27}$ S. Bannerjee, M. K. Sanyal, A. Datta, S. Kanakaraju, and S. Mohan, Phys. Rev. B 54, 16373 (1996).

${ }^{28}$ W. H. Weber, K. C. Hass, and J. R. McBride, Phys. Rev. B 48, 178 (1993).

${ }^{29}$ P. M. Fauchet and I. H. Campbell, Crit. Rev. Solid State Mater. Sci. 14, S79 (1988).

${ }^{30}$ P. Sutter, C. Schwarz, E. Muller, V. Zelezny, S. GonacalvesConto, and H. von Kanel, Appl. Phys. Lett. 65, 2220 (1994).

${ }^{31}$ P. D. Pearson, A. F. Ruppert, B. Abeles, and T. Tiedje, Phys. Rev. B 32, 5558 (1985).

${ }^{32}$ J. Groenen, R. Carles, S. Christiansen, M. Albrecht, W. Dorsch, H. P. Strunk, H. Wawra, and G. Wagner, Appl. Phys. Lett. 71, 3856 (1997).

${ }^{33}$ M. A. Renucci, J.-B. Renucci, and M. Cardona, in Proceedings of the Conference on Light Scattering in Solids, edited by M. Balkanski (Flammarion, Paris, 1971).

${ }^{34}$ R. Schorer, E. Feriess, K. Eberl, and G. Abstreiter, Phys. Rev. B 44, 1772 (1991).

${ }^{35}$ D. J. Eaglesham, F. C. Unterwald, and D. C. Jacobson, Phys. Rev. Lett. 70, 966 (1993).

${ }^{36}$ T. Ohno, Phys. Rev. Lett. 73, 460 (1994).

${ }^{37}$ B. D. Yu and A. O. Shimaya, Phys. Rev. Lett. 72, 3190 (1994).

${ }^{38}$ C. W. Oh, E. Kim, and Y. H. Lee, Phys. Rev. Lett. 76, 776 (1996).

${ }^{39}$ Z. H. Ming, Y. L. Suo, H. Huang, Y. H. Kao, J. C. Tsang, and S. S. Iyer, Appl. Phys. Lett. 65, 1382 (1994).

${ }^{40}$ M. Katayama, T. Nagayana, M. Aono, and C. F. Mcconville, Phys. Rev. B 54, 8600 (1996).

${ }^{41}$ M. Horn-von Hoegen, M. Copel, J. C. Tsang, M. C. Ruter, and R. M. Tromp, Phys. Rev. B 50, 10811 (1994).

${ }^{42}$ V. A. Gaisler, I. G. Neizvestayi, M. P. Sinyukor, and A. B. Talochlein, Pis'ma Zk Eksp. Teor. Fiz. 45, 347 (1987) [JETP Lett. 45, 441 (1987)].

${ }^{43}$ S. Hayashi, H. Wakayama, T. Okada, S. S. Kim, and K. Yamamoto, J. Phys. Soc. Jpn. 56, 243 (1987). 